\title{
SOSIALISASI BELA NEGARA WAWASAN KEBANGSAAN DAN NILAI- NILAI DASAR DI SMPN 1 JAGOI BABANG KABUPATEN BENGKAYANG
}

\author{
*Fajar Wulandari ${ }^{1)}$, Rika Wahyuni ${ }^{2)}$, Heru Susanto ${ }^{3)}$, Insan Suwanto ${ }^{4)}$ \\ 1) Pendidikan Guru Sekolah Dasar, STKIP Singkawang,e-mail: fajarwulandari3@gmail.com* \\ 2) Pendidikan Matematika, STKIP Singkawang, email : rikawahyuni142@gmail.com \\ 3) Pendidikan Bahasa Indonesia, STKIP Singkawang, e-mail : anto_eru@yahoo.co.id \\ 4) Pendidikan Bimbingan dan Konseling, STKIP Singkawang, e-mail : insansuwanto@gmail.com
}

\begin{abstract}
Abstrak
Pelaksanaan di dalam pengabdian kepada masyarakat ini ditujukan dalam kegiatan Bela Negara adalah suatu sikap, tekad dan tindakan warga negara yang teratur, menyeluruh, terpadu, berlanjut yang dilandasi oleh kecintaan pada tanah air, kesadaran berbangsa dan bernegara Indonesia, keyakinan akan kesaktian. Pancasila sebagai ideologi negara, dan dan kerelaan untuk berkorban guna meniadakan setiap ancaman baik dari luar maupun dari dalam negeri yang membahayakan kemerdekaan dan kedaulatan negara, kesatuan dan persatuan bangsa, keutuhan wilayah dan yurisdiksi nasional, serta nilai-nilai Pancasila dan UUD 1945. Wawasan kebangsaan dapat diartikan sebagai konsepsi cara pandang yang dilandasi akan kesadaran diri sebagai warga dari suatu negara akan diri dan lingkungannya di dalam kehidupan berbangsa dan bernegara. Wawasan kebangsaan dan nilai-nilai dasar bela negara diterapkan untuk meningkatkan pengetahuan dan wawasan tentang landasan kehidupan berbangsa dan bernegara, nilai-nilai dasar bela negara, penghormatan terhadap lambang-lambang negara dan ketaatan kepada peraturan perundang-undangan, dan pembinaan kerukunan, menjaga persatuan dan kesatuan bangsa. Sosialisai bela negara tentang wawasan dan nilai-nilai dasar dilakuan pada siswa kelas VII di SMPN 1 Jagoi Babang. Siswa kelas VII di SMPN 1 Jagoi Babang cukup matang dalam menerima materi dan himbauan dalam sosialisasi tersebut sehingga materi yang disampaikan moderator dpat diterima dengan baik. Para siswa yang berdomisili di daerah perbatasan Malaysia-Indonesia (Malindo) diharapkan juga memiliki nasionalisme terhadap tanah airnya.
\end{abstract}

Kata Kunci: Bela Negara,Wawasan Kebangsaan dan Nilai-nilai dasar.

\begin{abstract}
Implementation in this community service is aimed at State Defense activities, which is an attitude, determination and action of citizens who are orderly, comprehensive, integrated, continuing based on love for the homeland, awareness of the nation and state of Indonesia, belief in supernatural powers. Pancasila as the state ideology, and the willingness to sacrifice to eliminate every threat both from outside and from within the country that endangers the independence and sovereignty of the state, national unity and unity, territorial integrity and national jurisdiction, as well as the values of Pancasila and the 1945 Constitution. can be interpreted as a conception of a perspective based on self-awareness as citizens of a country of themselves and their environment in the life of the nation and state. National insight and basic values of state defence are applied to increase knowledge and insight into the foundations of national and state life, basic values of state defence, respect for state symbols and obedience to laws and regulations, and fostering harmony, maintaining unity and national unity. State defence socialization about basic insights and values was carried out to grade VII students at SMPN 1 Jagoi Babang. The seventh-grade students at SMPN 1 Jagoi Babang were mature enough to accept the material and appeals in the socialization so that the material presented by the moderator was well received. Students who live in the Malaysia-Indonesia border area (Malindo) are also expected to have nationalism towards their homeland.
\end{abstract}

Keywords: State Defense, National Insights and basic values 


\section{PENDAHULUAN}

Bela negara adalah istilah konstitusi yang terdapat dalam pasal 27 ayat (3) UUD Negara Republik Indonesia Tahun 1945 yang berbunyi "setiap warga negara berhak dan wajib ikut serta dalam upaya pembelaan negara”. Bela Negara adalah sebuah konsep yang disusun oleh perangkat perundangan dan petinggi suatu negara tentang patriotisme seseorang, suatu kelompok atau seluruh kompone dari suatu Negara dalam kepentinga mempertahankan eksistensi negara tersebut (Departemen Pendidikan Nasional, 2002). Setiap warga negara memiliki kewajiban yang sama dalam masalah pembelaan negara. Hal tersebut merupakan wujud kecintaan seorang warga negara pada tanah air yang sudah memberikan kehidupan padanya (Alfaqi,2016). Hal ini terjadi sejak seseorang lahir, tumbuh dewasa serta dalam upayanya mencari penghidupan. Secara fisik, hal ini dapat diartikan sebagai usaha pertahanan menghadapi serangan fisik atau agresi dari pihak yang mengancam keberadaan negara tersebut, sedangkan secara nonfisik konsep ini diartikan sebagai upaya untuk serta berperan aktif dalam memajukan bangsa dan negara, baik melalui pendidikan, moral, sosial maupun peningkatan kesejahteraan orang-orang yang menyusun bangsa tersebut (Dudu Dswara M, 2001) (Hans Kohn, 1955).

Dalam Undang-undang Republik Indonesia Nomor 3 tahun 2002 tentang Pertahanan Negara, pasal 9 dinyatakan bahwa; Setiap warga negara berhak dan wajib ikut serta dalam upaya bela Negara yang diwujudkan dalam penyelenggaraan pertahanan negara. Selanjutnya keikutsertaan warga Negara diselenggarakan melalui (1) pendidikan kewarganegaraan, (2) pelatihan dasar kemiliteran secara wajib (3) pengabdian sebagai Tentara Nasional Indonesia (TNI) secara sukarela atau wajib (4) pengabdian sesuai dengan profesi (Kusuma Meida, 2013).

Bela Negara adalah sikap dan tindakan warga negara yang teratur menyeluruh terpadu dan berlanjut yang dilandasi oleh

1. Cinta Tanah Air; yaitu mencintai ruang wilayah negara baik secara geografis, maupun tata nilai dan tata kehidupan masyarakat yang telah memberikan sumber kehidupan dan penghidupan, sejak manusia lahir sampai pada akhir hayatnya.

2. Kesadaran Berbangsa dan Bernegara; yaitu suatu sikap dan tingkah laku yang sesuai dengan kepribadian bangsa dan selalu mengkaitkan dirinya dengan cita-cita dan tujuan hidup bangsanya, tumbuh rasa kesatuan, persatuan Bangsa Indonesia, memiliki jiwa besar dan patriotisme serta memiliki kesadaran atas tanggungjawab sebagai warga negara.

3. Yakin akan Pancasila sebagai ideologi negara dan pandangan hidup bangsa; yaitu melaksanakan Pancasila sebagai sumber hukum sekaligus sebagai kerangka acuan NKRI karena Pancasila telah dapat mempersatukan Rakyat Indonesia yang terdiri dari beranekaragam agama, suku bangsa, bahasa, asal-usul keturunan.

4. Rela Berkorban untuk Bangsa dan Negara, artinya seluruh warga Negara dituntut rela berkorban dengan mendahulukan kepentingan umum dari pada kepentingan pribadi/golongan.

5. Memiliki Kemampuan Awal Bela Negara; artinya secara psikis, setiapwarga negara dituntut untuk memilikisikap perilaku dispilin, ulet, kerjakeras, taat aturan, percaya padakemampuan sendiri, tahan ujipantang menyerah, sedangkan secara fisik memiliki kesehatan prima dan tangkas hal tersebut sejalan denganpepatah kuno yaitu dalam badan sehat terdapat jiwa yang kuat (Rahayu,2019) (Maftuh B, 2008).

Pelaksanaan pembelaan negara, seorang warga bisa melakukannya baik secara fisik maupun non fisik. Pembelaan negara secara fisik diantaranya dengan cara perjuangan mengangkat senjata apabila ada serangan dari negara asing terhadap kedaulatan bangsa. Sementara, pembelaan Negara secara non fisik diartikan sebagai semua usaha untuk menjaga bangsa serta kedaulatan negara melalui proses peningkatan nasionalisme. Nasionalisme adalah rangkaian kecintaan dan kesadaran dalam proses berkehidupan dalam negara dan bangsa, serta upaya untuk menumbuhkan rasa cinta pada tanah air. Selain itu, pembelaan bisa dilakukan dengan cara menumbuhkan keaktifan dalam berperan aktif untuk mewujudkan kemajuan bangsa dan negara (LAN RI, 2014).

Wawasan kebangsaan dalam bela negara minimal didasari oleh membiasakan belajar disiplin, 
kerjasama dalam solidaritas, tanggungjawab dan membentuk pribadi yang unggul Kesadaran bela negara adalah berupaya untuk mempertahankan negara dari ancaman yang dapat mengganggu kelangsungan hidup bermasyarakat yang berdasarkan atas cinta tanah air. Kesadaran bela negara juga dapat menumbuhkan rasa patriotism dan nasionalisme didalam diri masyarakat. Upaya bela negara selain sebagai kewajiban dasar juga merupakan kehormatan bagi setiap warga negara yang dilaksanakan dengan penuh kesadaran, penuh tanggung jawab dan rela berkorban dalam pengabdian kepada negara dan bangsa. Keikutsertaan kita dalam bela negara merupakan bentuk cinta terhadap tanah air. Nilai-nilai bela negara yang harus lebih dipahami penerapannya dalam kehidupan masyarakat berbangsa dan bernegara antara lain: 1) Cinta Tanah Air. Negeri yang luas dan kaya, melestarikan budaya-budaya yang ada, menjaga lingkungan dan pastinya menjaga nama baik negara. 2) Kesadaran Berbangsa dan Bernegara. Kesadaran berbangsa dan bernegara merupakan sikap kita yang harus sesuai dengan kepribadian bangsa yang selalu dikaitkan dengan cita-cita dan tujuan hidup bangsanya. 3) Pancasila. Pancasila bukan hanya sekedar teoritis dan normative saja tapi juga diamalkan dalam kehidupan sehari-hari. 4) Rela berkorban untuk Bangsa dan Negara. Dalam wujud bela negara tentu saja harus rela berkorban untuk bangsa dan negara. 5) Memiliki Kemampuan Bela Negara. Kemampuan bela negara itu sendiri dapat diwujudkan dengan tetap menjaga kedisiplinan, ulet, bekerja keras dalam menjalani profesi masing-masing. Kesadaran bela negara dapat diwujudkan dengan cara ikut dalam mengamankan lingkungan sekitar seperti menjadi bagian dari Siskamling, membantu korban bencana sebagaimana diketahui bahwa Indonesia sering sekali mengalami bencana alam, menjaga kebersihan minimal kebersihan tempat tinggal sendiri, mencegah bahaya narkoba yang merupakan musuh besar bagi generasi penerus bangsa, mencegah perkelahian antar perorangan atau antar kelompok karena di Indonesia sering sekali terjadi perkelahian yang justru dilakukan oleh para pemuda, cinta produksi dalam negeri agar Indonesia tidak terus menerus mengimpor barang dari luar negeri, melestarikan budaya Indonesia dan tampil sebagai anak bangsa yang berprestasi baik khususnya kepada siswa SMPN 1 Jagoi Babang.

SMPN 1 Jagoi Babang kabupaten Bengkayang terletak didaerah perbatasan antara negara Indonesia dengan Malaysia terletak di Jl. Raya Jagoi, Jagoi, Kec. Jagoi Babang, Kab. Bengkayang, Prov. Kalimantan Barat. Jumlah guru 14 Orang, siswa laki-laki 110 Orang, siswa perempuan 108 orang, ombongan belajar 8 , jumlah kelas 6 ruang, laboratorium 1, perpustakaan 1 dan sudah menggunakan kurikulum 2013. Tujuan dari kegiatan ini yaitu memberikan pengetahuan baru untuk siswa dan guru SMPN 1 Jagoi Babang. Sasaran utama dari kegiatan ini adalah siswa kelas VII yang baru tamat dari SD dan memasuki SMP kelas VII karena dengan adanya sosialisasi ini dapat menambah pemikiran yang baik untuk siswa kelas VII agar mampu mengerti tentang bela Negara khususnya kepada materi wawasan kebangsaan dan nilai-nilai dasar bela negara agar siswa-siswa tersebut bisa menjadi penerus bangsa yang baik.

\section{TINJAUAN PUSTAKA}

Nasionalisme merupakan seSuatu yang sangat penting bagi kehidupan berbangsa dan bernegara. Karena dengan nasionalisme yang tinggi sebuah bangsa dapat berdiri tegak dan memiliki sebuah jati diri yang kuat. Nasionalisme merupakan sesuatu yang harus diperhatikan oleh setiap elemen bangsa dalam setiap perjalanan bangsa tersebut, begitu pula dengan Indonesia (Alfaqi,2016). Nasionalisme merupakan suatu sikap yang wajib dimiliki oleh semua insan yang memiliki identitas sebagai warga Negara. Tindakan yang dapat dilakukan dalam menjaga kesatuan NKRI yaitu salah satunya dengan memberikan wawasan kebangsaan bagi masyarakat ataupun peserta didik agar lebih mencintai negaranya. Hal tersebut dapat dilakukan dengan proses belajar mengajar.

Penjelasan Undang-undang No. 20 Tahun 2003 tentang Sistem Pendidikan Nasional dinyatakan bahwa Pendidikan Kewarganegaraan dimaksudkan untuk membentuk peserta didik menjadi manusia yang memiliki rasa kebangsaan dan cinta tanah air.

Pendidikan Kewarganegaraan yang sesuai untuk masa kini adalah adalah membina warganegara Indonesia yang baik, yakni warganegara yang beriman dan bertaqwa kepada 
Tuhan Yang Maha Esa, yang memiliki jiwa yang merdeka, memahami dan menjalankan hak dan kewajiban dengan baik, memiliki rasa kebangsaan dan cinta tanah air, memiliki kepekaan dan tanggung jawab sosial, berjiwa demokratis, mampu menghargai perbedaan etnis, budaya dan agama, mampu berfikir kritis, sistematis, kreatif, dan inovatif, mampu mengambil keputusan dan memecahkan masalah secara demokratis, menyelesaikan konflik secara damai tanpa kekerasan, mematuhi hukum, berdisiplin, menghargai lingkungan hidup, dan mampu berpartisipasi secara cerdas dalam kehidupan politik lokal, nasional, dan global (Maftuh, 2018).

Pendidikan Kewarganegaraan pada masa sekarang ini memiliki misi sebagai berikut:

1. PKn sebagai pendidikan politik, yang berarti program pendidikan ini memberikan pengetahuan, sikap dan keterampilan kepada siswa agar mereka mampu hidup sebagai warga negara yang memiliki tingkat kemelekan politik (political literacy) dan kesadaran berpolitik (political awareness), serta kemampuan berpartisipasi politik (political participation) yang tinggi.

2. PKn sebagai pendidikan nilai (value education), yang berarti melalui PKn diharapkan tertanam dan tertransformasikan. Internalisasi Nilai-Nilai Pancasila dan Nasionalisme Melalui Pendidikan Kewarganegaraan nilai, moral, dan norma yang dianggap baik oleh bangsa dan negara kepada diri siswa, sehingga mendukung bagi upaya nation and character building. Dalam hal ini, nilai-nilai Pancasila tetap harus menjadi rujukan utama dalam upaya pendidikan nilai ini.

3. PKn sebagai pendidikan nasionalisme, yang berarti melalui PKn diharapkan dapat ditumbuhkan dan ditingkatkan rasa kebangsaan atau nasionalisme siswa, sehingga mereka lebih mencintai, merasa bangsa, dan rela berkorban untuk bangsa dan negaranya.

4. PKn sebagai pendidikan hukum, yang berarti

1. bahwa program pendidikan ini diarahkan

2. untuk membina siswa sebagai warga Negara yang memiliki kesadaran hukum yang tinggi, yang menyadari akan hak dan kewajibannya, dan yang memiliki kepatuhan terhadap hukum yang tinggi.
5. PKn sebagai pendidikan multikulural (multiculutal education), yang berarti PKn diharapkan mampu meningkatkan wawasan dan sikap toleran siswa dan mahasiswa untuk hidup dalam masyarakatnya yang multikutural.

6. PKn sebagai pendidikan resolusi konflik (conflict resolution education), yang berarti PKn membina siswa dan mahasiswa untuk mampu menyelesaikan konflik secara konstruktif.

Sosialisasi bela Negara yang dberikan dalam pelaksaannya kegiatan ini juga mengandung nilainilai seperti (Widodo,2011):

1. Cinta Tanah Air dengan indikator:

- Menjaga tanah dan pekarangan serta seluruh ruang wilayah Indonesia

- Jiwa dan raganya sebagai bangsa Indonesia

- Memiliki jiwa patriotisme terhadap bangsa dan Negara

- Menjaga nama baik bangsa dan Negara

- Memberikan konstribusi pada kemajuan bangsa dan negara

2. Kesadaran berbangsa dan bernegara dengan indikatornya:

- Ikut aktif dalam organisasi kemasyarakat, profesi maupun politik.

- Menjalankan hak dan kewajiban sebagai warga negara sesuai dengan peraturan perundangundangan yang berlaku.

- Ikut serta dalam pemilihan umum.

- Berpikir, bersikap, dan berbuat yang terbaik bagi bangsa dan Negara

- Berpartisipasi dalam menjaga kedautan bangsa dan negara

3. Yakin Pancasila sebagai Ideologi Negara, dengan indikatornya:

- Memahami nilai-nilai dalam Pancasila.

- Mengamalkan nilai-nilai pancasila dalam kehidupan sehari-hari

- Menjadikan Pancasila sebagai pemersatu bangsa dan negara.

- Senantiasa mengembangkan nilai

- Pancasila.

- Yakin dan percaya bahwa pancasila sebagai dasar negara.

4. Rela berkorban untuk bangsa dan negara, dengan indikator: 
- Bersedia mengorbankan waktu, tenaga dan pikirannya untuk kemajuan bangsa dan Negara

- Siap membela bangsa dan negara dari berbagai ancaman

- Berpartisipasi aktif dalam pembangunan masyarakat, bangsa dan negara.

5. Yakin dan percaya bahwa pengorbanan untuk bangsa dan negaranya tidak sia-sia.

- Memiliki Kesiapan Fisik dan Psikis, dengan indikator:

- Memiliki Kecerdasan emosional dan spiritual serta intelegensia.

- Senantiasa memelihara jiwa dan raganya

- Senantiasa bersyukur dan berdo'a atas kenikmatan yang telah diberikan Tuhan YME.

- Gemar berolah raga

- Senantiasa menjaga kesehatan.

\section{METODOLOGI PENGABDIAN}

Pelaksanaan pengabdian kepada masyarakat ini menggunakan metode sosialisasi dan berdiskusi bersama dengan siswa-siswa di SMPN 1 Jagoi Babang, dengan menggunakan metode PAR (Participatory Action Research). Pendekatan PKM dengan Participatory Action Research (PAR) merupakan pendekatan yang prosesnya bertujuan untuk pembelajaran dalam mengatasi masalah dan pemenuhan kebutuhan praktis masyarakat, serta produksi ilmu pengetahuan, dan proses perubahan sosial keagamaan. Oleh karena itu, pendekatan ini merupakan sarana untuk membangkitkan kesadaran kritis secara kolektif atas adanya belenggu-belenggu idologi globalisasi neoliberal dan belenggu paradigma keagamaan normatif yang menghambat proses transformasi sosial keagamaan.

Program ini menitikberatkan kepada siswa melaui pemberian informasi terkait dengan Bela Negara di lingkungan sekolah khususnya kepada siswa di SMPN 1 Jagoi Babang, Kabupaten Bengkayang, Kalimantan Barat. sersama dengan jajaran TNI-AD Yonif Raider 641/Beruang, yang sedang menjaga kesatuan NKRI dan melaksanakan tugas perbatasan di perbatasan Malaysia dan Indonesia (Malindo). Selanjutnya penyampaian dari isi materi sosialisasi dan dimulai oleh moderator, namun tidak terlepas dari peralatan yang dapat menunjang berlangsungnya sosialisasi tersebut, adapun seperti proyektor, layar tampilan, pengeras suara dan laptop sebagai alat untuk mengoprasikan materi serta video dari salah satu bentuk Bela Negara yang ditujukan kepada para siswa kelas VII SMPN 1 Jagoi Babang.

Metode tambahan yang digunakan adalah metode tanya jawab, metode ini membuat kegiatan menjadi lebih menarik karena adanya interaksi seperti menjelaskan dan dilanjutkan dengan tanya jawab antara peserta dan penyaji. Hal tersebut diharap pula dapat menambah wawasan kebangsaan para peserta yang menerima sosialisasi seputar Bela Negara.

\section{PELAKSANAAN KEGIATAN}

Pelaksanaan kegiatan pengabdian kepada masyarakat yang dilakukan team dari dosen STKIP Singkawang bersama dengan anggota TNI-AD yang mana bertempat di SMP Negeri 1 Jagoi Babang dalam rangkat untuk meningkatkan rasa nasionalisme dan rasa cinta terhadap tanah air.

Kegiatan pengabdian tersebut dengan memberikan materi terkait wawasan kebangsaan oleh anggota TNI-AD yang sedang bertugas menjaga perbatasan NKRI dengan Negara tetangga Malaysia bersama tim dosen STKIP Singkawang, dengan menggunakan media pembelajaran video siswa diberikan pemahaman dan pembelajaran terkait wawasan kebangsaan. selain itu siswa ditumbuhkan rasa semangatnya dengan menyanyikan yel yel dengan lagu nasionalisme, kegiatan berjalan sangat menarik hingga akhrir kegiatan pun terdapat aspirasi dari siswa yang mulai dapat memahami bahwa pentingnya sikap nassionalisme yang wajib mereka (siswa) miliki mengingat letak geografis atau lokasi yang berada dekat dengan perbatasan Negara lain. Selain itu kegiatan sosialsisasi wawasan kebangsanaan dan materi terkait bela Negara dirasa telah memberikan manfaat kepada generasi muda dan calon penerus bangsa yang berada di daerah perbatasan Malindo (Malaysia - Indonesia).

\section{HASIL DAN PEMBAHASAN}

Sosialisasi bela negara ini didukung dari sekolah SMPN 1 Jagoi Babang dimulai dari orientasi 
dan sosialisasi. Pada saat orientasi ini sekaligus dilakukan perijinan kegiatan pelaporan kepada Kepala Sekolah SMPN 1 Jagoi Babang, wakil Kepala sekolah, guru dan staf di SMPN 1 Jagoi Babang. Sasaran kegiatan sosialisasi ini mdilakukan kepada seluruh siswa kelas VII SMPN 1 Jagoi Babang.

Hasil evaluasi pada sosialisasi ini menunjukan bahwa mahasiswa mampu memberikan materi berkaitan dengan sosialisasi kepada siswakelas VII berkaitan dengan materi bela negara. Secara keseluruhan, siswa dapat menerima materi yang disampaikan oleh moderator. Hal ini dilihat dari proses tanya jawab yang diberikan oleh moderator kepada siswa kelas VII. Pelaksanaan kegiatan pengabdian tersebut dipaparkan melalui gambar 1 sampai Gambar 3

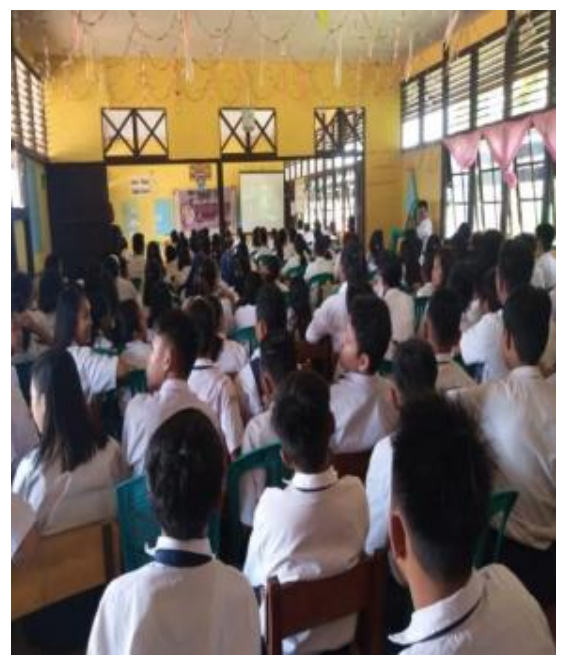

Gambar 1. Peserta Kegiatan Sosialisasi Bela Negara

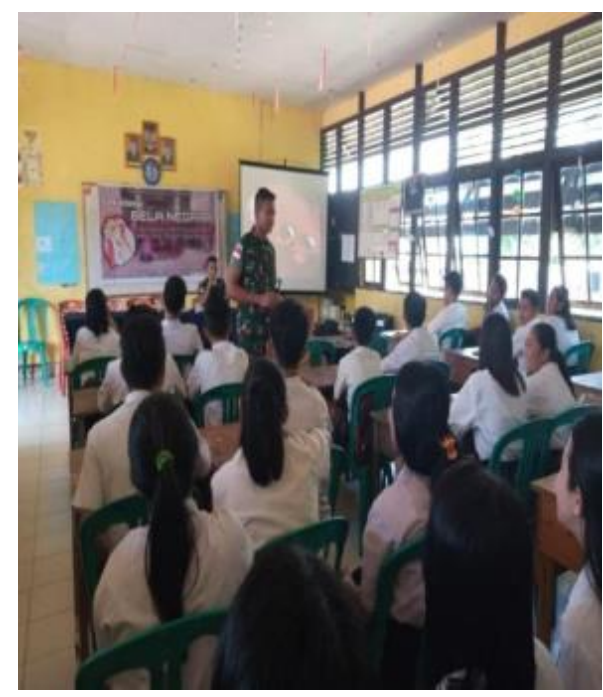

Gambar 2. Penyaji memberikan materi bela negara

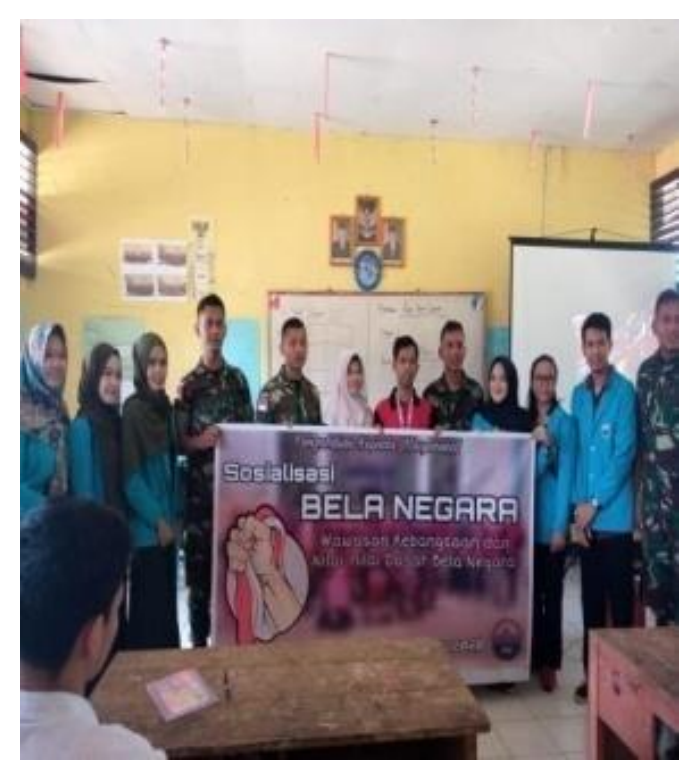

Gambar 3. Foto Bersama penyaji

Gambar 1 dan 2 menerangkan bahwa peserta yang mengikuti sosialisasi dilaksanakan pada seluruh siswa kelas VII di SMPN 1 Jagoi Babang. Materi yang diberikan sederhana dan ringan agar mudah diterima oleh kalangan para siswa. Dalam prosesnya para siswa dibangun jiwa nasionalismenya melalui menyanyikan lagu dan yel-yel sehingga tetap terjaga semangat para siswa dalam memahami materi bela negara yang diberikan oleh penyaji. Setelah materi selesai diberikan maka diakhiri dengan sesi dokumentasi yang mana guna kebutuhan dari bukti pelaksanaan kegiatan pengabdian kepada masyarakat ini. Kegiatan sosialisasi tersebut sudah memberikan tambahan pengetahuan terkait dengan wawasan kebangsaan khususnya pada pembelajaran PKN. Hal tersebut juga memerlukan kegiatan praktik dengan melakukan atau membuat suatu contoh dari bela negara.

\section{Ucapan Terima Kasih}

Ucapan terimakasih kepada Kepala Sekolah, Guru dan Siswa SMPN1 Jagoibabang yang telah bersedia menerima penulis dengan baik dan memfasilitasi mahasiswa dalam bentuk sarana dan prasarana serta mahasiswa KKN STKIP Singkawang". 


\section{PENUTUP}

\section{Kesimpulan}

Kegiatan pengabdain pada masyarakt yang dilakukan melaluisosialisasi bela Negara kepada siswa-siswa kelas VII di SMPN 1 Jagoibabang telah menyelesaikan seperti di bawah ini:

1. Kegiatan sosialisasi bela Negara mendapat respon yang positif dari siswa, kepala sekolah SMPN 1 Jagoibabang beserta guru dan staf.

2. Sosialilasi ini berjalan dengan baik dan dapat menambahi ilmu dan wawasan baru bagi siswa SMPN 1 Jagoibabang khususnya kelas VII.

3. Sosialisasi bela negara dengan materi PKn yang diaplikasikan dengan pembelajaran IPS dan materi wawasan kebangsaan telah menanamkan nilai-nilai dasar bela negara kepada seluruh siswa yang mengikuti sosialisasi Bela Negara di SMPN 1 Jagoi Babang.

\section{Saran}

Pengabdian kepada masyarakat dan peserta didik di daerah perbatasan perlu dilakukan lebih lanjut, karena rentannya daerah perbatasan yang berbatasan dengan Negara tetangga menawarkan banyak fasilitas. Untuk program pengabdian yang selanjutnya diharapkan dapat dilakukan program setiap semester sehingga dapat membangun pondasi yang kuat akan pengetahuan bela Negara dan cinta tanah air bagi masyarakat dan peserta didik di daerah perbatasan khususnya perbatasan Malindo (Malaysia-Indonesia).

\section{DAFTAR PUSTAKA}

Alfaqi, Mifdal Z. 2016. Melihat Sejarah Nasionalisme Indonesia Untuk Memupuk Sikap Kebangsaan Generasi Muda. Jurnal Civics Volume 13 Nomor 2, Desember 2016

Departemen Pendidikan Nasional. 2002. Kamus Besar Bahasa Indonesia.Jakarta: Balai Pustaka.

Dudu Dswara M. 2001. Pengantar Ilmu Hukum. Bandung: Refika Aditama.

Hans Kohn. 1955. Nationalism Its Meaning and History. New York: D. Van Nostrand Company, Inc.

Kusuma Meida. 2013. Muatan Materi Pendidikan Bela Negara (Analisis Isi Pada Buku
Pendidikan Kewarganegaraan Kelas IX Karangan Agus Dwiyono Dkk Serta Pelaksanaannya Di SMP Muhammadiyah 7 Sumberlawang Kabupaten Sragen Tahun Ajaran 2012/2013). Surakarta.

LAN RI. 2014. Modul Prajab: Sistem Administrasi Negara Republik Indonesian (SANKRI). Jakarta: Lembaga Administrasi Negara.

Maftuh, B. 2008. Internalisasi Nilai-Nilai Pancasila dan Nasionalisme Melalui Pendidikan Kewarganegaraan. EDUCATIONIST Vol. II No. 2 Juli 2008. ISSN: $1907-8838$.

Norman K. Denzin dan Yvonnas S. Lincoln, Handbook of Qualitative Research, (Yogjakarta: Pustaka Pelajar, 2009). Hal. 422

Oetjo Usman dan Alfian. 1991. Pancasila Sebagai Ideologi Dalam Berbagai Bidang Kehidupan Bermasyarakat, Berbangsa, dan Bernegara. Jakarta: Badan Pembinaan Pendidikan Pelaksanaan Pedoman Penghayatan dan Pengamalan Pancasila (BP-7) Pusat.

Rahayu, M. Dkk. 2019. Kesadaran Bela Negara Pada Mahasiswa. Epigram Vol. 16 No. 2 Oktober 2019

Suhady, Idup dan A. M. Sinaga. 2006. Wawasan Kebangsaan Dalam Kerangka NKRI. Jakarta: Lembaga Administrasi Negara - Republik Indonesia.

Undang-Undang Dasar Negara Republik Indonesia Tahun 1945

Undang-undang Republik Indonesia Nomor 3 tahun 2002 tentang Pertahanan Negara

Undang-undang No. 20 Tahun 2003 tentang Sistem Pendidikan Nasional.

Wantanas. 2018. Modul Utama Pembinaan Bela Negara, Modul 1: Konsepsi Bela Negara dan Modul 2: Implementasi Bela Negara. Jakarta: Dewan Ketahanan Nasional RI.

Widodo, S. 2011. Implementasi Bela Negara Untuk Mewujudkan Nasionalisme. Jurnal Ilmiah CIVIS, Volume I, No 1, Januari 2011. 